\title{
Characterization of NaA Zeolite Oxygen Permeable Membrane on $\mathrm{TiO}_{2} / \alpha-\mathrm{Al}_{2} \mathrm{O}_{3}$ Composite Support
}

\author{
ZHU Mengfu ${ }^{1, a^{*}}$, SU Hongbo ${ }^{1, b}$, DENG Cheng ${ }^{1, \mathrm{c}}$, YUWEN Linlin ${ }^{1, \mathrm{~d}}$ and JIANG \\ Mingming ${ }^{1, \mathrm{e}}$ \\ ${ }^{1}$ Institute of Medical Equipment, Academy of Military Medical Sciences,Tianjin,China \\ a zmf323@163.com, ${ }^{\mathrm{b}}$ hongbo25@163.com, ${ }^{\mathrm{c} d c n u d t @ 163 . c o m,}{ }^{\mathrm{d}} 11323 @ 163 . c o m,{ }^{\mathrm{e}} \mathrm{jmm} 323 @ 163 . c o m$
}

\begin{abstract}
The NaA zeolite membrane was synthesized on the surface of $\mathrm{TiO}_{2} / \alpha-\mathrm{Al}_{2} \mathrm{O}_{3}$ composite support with $\mathrm{TiO}_{2}$ as modifier of $\alpha-\mathrm{Al}_{2} \mathrm{O}_{3}$ porous tubular ceramic membrane support by crystallization method. The structure characterization indicated that the $\mathrm{TiO}_{2}$ of the support surface could effectively improve the surface properties of the support. It didn't affect the crystallization of $\mathrm{NaA}$ synthesis liquid and synthesis process of $\mathrm{NaA}$ zeolite membrane. There were no obvious defects between the crystal particles with size of approximate $6 \mu \mathrm{m}$. The perfect and complete membrane with thickness of approximate $15 \mu \mathrm{m}$ combined closely with support to connection together by $\mathrm{TiO}_{2}$ modified. The oxygen permeability of the membrane on $\mathrm{TiO}_{2} / \alpha-\mathrm{Al}_{2} \mathrm{O}_{3}$ composite support improves of $47 \%$ compared with that of $\alpha-\mathrm{Al}_{2} \mathrm{O}_{3}$ support. So the process of $\mathrm{TiO}_{2}$ modifying the surface of $\alpha-\mathrm{Al}_{2} \mathrm{O}_{3}$ support should increase the oxygen permeability of the $\mathrm{NaA}$ zeolite membrane.
\end{abstract}

Keyword: NaA zeolite; zeolite membrane; composite support; crystal seed method; oxygen permeation

\section{Introduction}

The oxygen-enriched gas is enriched by membrane process from air according to the different permeation rate of oxygen and nitrogen through the membrane under certain pressure. Because of the permeation of oxygen is faster than that of nitrogen, oxygenenriched gas can be separated by membrane. Compared with organic polymer membrane, inorganic membrane shows a broad application prospect with its high separation selectivity, fine thermal stability and chemical stability in the field of gas separation [1-3]. Zeolite is a kind of inorganic crystalline materials with uniform and molecular-sized channels. Molecules with different sizes and shapes can be discriminated or separated by zeolites through their channels. NaA zeolite membrane is an inorganic membrane formed by $\mathrm{NaA}$ zeolite molecular sieve with microporous aluminum silicate crystals and molecular pore size. NaA zeolite molecular sieve is one of the microporous crystalline alumino

*Corresponding author: zmf323@163.com 
silicate zeolites which have a channel opening pore size of $0.41-0.43 \mathrm{~nm}$, a low $\mathrm{Si} / \mathrm{Al}$ ratio and strong hydrophilicity. The pore size is close many molecular kinetic diameters and makes the separation of small molecules by difference in size possible. NaA zeolite molecular sieve preparation processes include hydrothermal synthesis, secondary growth and microwave synthesis [4-9]. The interface stability, forming mechanism and membrane performance have a great influence on the preparation of $\mathrm{NaA}$ zeolite membrane, especially the pore size and the surface properties of porous support which directly affect the quality of the membrane[10]. The $\alpha-\mathrm{Al}_{2} \mathrm{O}_{3}$ porous material is a common support used to preparation of $\mathrm{NaA}$ zeolite membranes. Because of its strong hydrophobicity and poor affinity with $\mathrm{NaA}$ zeolite, the zeolite membrane prepared by hydrothermal synthesis process on $\alpha-\mathrm{Al}_{2} \mathrm{O}_{3}$ support is with more thickness, smaller gas permeability and more defects. So its surface should to be modified [11-12]. To improve the integrity of NaA zeolite membrane, the $\mathrm{TiO}_{2} / \alpha-\mathrm{Al}_{2} \mathrm{O}_{3}$ composite support was prepared using $\mathrm{TiO}_{2}$ as modifier by coating process on the basis of preparation of $\mathrm{NaA}$ zeolite membrane on $\alpha$ $\mathrm{Al}_{2} \mathrm{O}_{3}$ support [13-14]. The NaA zeolite membrane on $\mathrm{TiO}_{2} / \alpha-\mathrm{Al}_{2} \mathrm{O}_{3}$ porous composite support was prepared by pre-coated crystal process, and its structure and oxygen permeability were characterized.

\section{Experimental}

\subsection{Preparation of $\mathrm{TiO}_{2} / \mathrm{a}-\mathrm{Al}_{2} \mathrm{O}_{3}$ composite support.}

The $\alpha-\mathrm{Al}_{2} \mathrm{O}_{3}$ ceramic membrane tube (pore size of $3 \mu \mathrm{m}$, porosity of $30 \%$, outer diameter of $12 \mathrm{~mm}$, and thickness of $2 \mathrm{~mm}$ and length of $100 \mathrm{~mm}$ ) was sealed at both ends. It was vertically immersed in $\mathrm{TiO}_{2}$ sol $\left(\mathrm{TiO}_{2}\right.$ content of $15 \%$, average particle size of $\left.15 \mathrm{~nm}\right)$ for $1 \mathrm{~min}$, pulled out at a constant speed. After dried at room temperature for $48 \mathrm{~h}$, placed into a muffle furnace to calcine for $1 \mathrm{~h}$ at $500^{\circ} \mathrm{C}$ at a certain heating rate, and cooled to room temperature. The $\mathrm{TiO}_{2} / \alpha-\mathrm{Al}_{2} \mathrm{O}_{3}$ composite support was prepared after repeat 3 times of immersing, drying and calcination.

\subsection{Pre-coating NaA zeolite seed.}

The synthesis liquid of $\mathrm{NaA}$ zeolite was composed of sodium silicate (analytic reagent grade), sodium aluminate (analytic reagent grade), sodium hydroxide (analytic reagent grade) and deionized water,and its composition $\mathrm{SiO}_{2}: \mathrm{Al}_{2} \mathrm{O}_{3}: \mathrm{Na}_{2} \mathrm{O}: \mathrm{H}_{2} \mathrm{O}=1.5: 1: 8: 600$ (in moles). The one end of the $\mathrm{TiO}_{2} / \alpha-\mathrm{Al}_{2} \mathrm{O}_{3}$ composite support was sealed. And another open end was placed in the synthesis liquid of $\mathrm{NaA}$ zeolite to coat with crystal for $2 \mathrm{~min}$ by vacuum seeding. After dried at room temperature for $24 \mathrm{~h}$, it was placed into a muffle furnace to calcine for $1 \mathrm{~h}$ at $500^{\circ} \mathrm{C}$ with a heating rate of $1{ }^{\circ} \mathrm{C} / \mathrm{min}$.

\subsection{Preparation of zeolite membrane.}

The $\mathrm{TiO}_{2} / \alpha-\mathrm{Al}_{2} \mathrm{O}_{3}$ support with pre-coating $\mathrm{NaA}$ zeolite seed was sealed the both ends to place into the synthesis liquid of $\mathrm{NaA}$ zeolite in the autoclave to crystallize for $4 \mathrm{~h}$ at $100^{\circ} \mathrm{C}$, then to cool to room temperature. The $\mathrm{NaA}$ zeolite membrane on $\mathrm{TiO}_{2} / \alpha-\mathrm{Al}_{2} \mathrm{O}_{3}$ porous composite support was prepared after repeat 3 times of crystallization. 


\subsection{Characterization.}

The NaA zeolite membranes were characterized by X-ray diffraction patterns (XRD,D8Discover type, Bruker Company Inc), sputtering deposition apparatus (SCD005 type, BALTEC Co), scanning electron microscope (SEM, Quanta 200 type, FEI Company) and gas permeation test device. XRD patterns can confirm the type and degree of molecular sieve crystallinity. SEM images can determine the continuity of membrane, the grain nature of crystal particle, the size and shape of crystal particle, the thickness of membrane, and the combined extent of membrane with support. The gas permeation test device can measure the oxygen permeability of membrane.

\section{Results and Discussion}

\subsection{Structure of composite support.}

The XRD patterns of support are shown in Fig. 1. The pattern of the $\mathrm{TiO}_{2} / \alpha-\mathrm{Al}_{2} \mathrm{O}_{3}$ composite support has an obvious $\mathrm{TiO}_{2}$ characteristic peak at $25^{\circ}$ corner and its intensity of characteristic peak significantly greater than that of $\alpha-\mathrm{Al}_{2} \mathrm{O}_{3}$ support. This indicates that the $\mathrm{TiO}_{2} / \alpha-\mathrm{Al}_{2} \mathrm{O}_{3}$ composite support prepared contains $\mathrm{TiO}_{2}$.

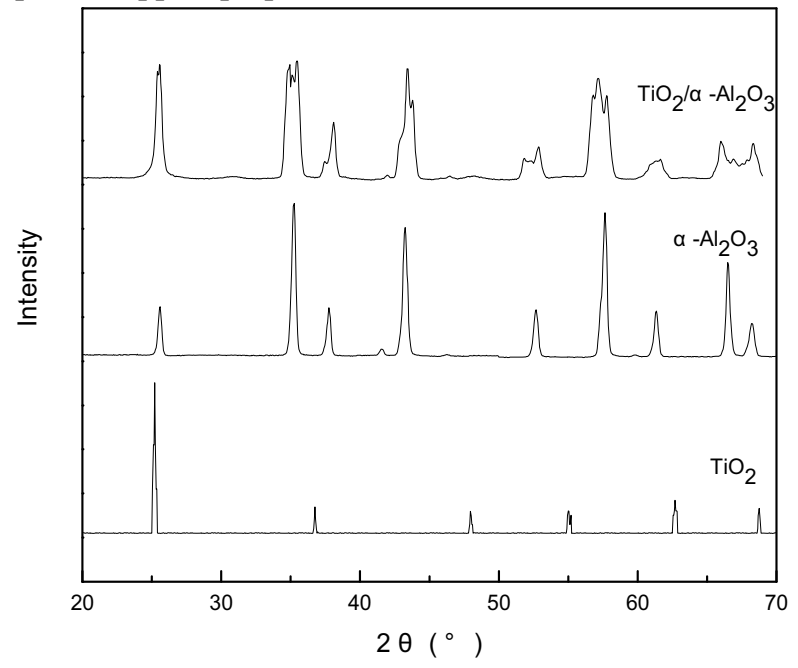

Fig.1 XRD patterns of the composite supports

Fig. 2 shows the SEM images of composite supports. It is found that the crystal of NaA zeolite seed(A) is a cube particle structure with crystal size of $5-7 \mu \mathrm{m}$, and clear and complete crystal particle. $\mathrm{TiO}_{2}$ particles completely fixed on the surface of $\alpha-\mathrm{Al}_{2} \mathrm{O}_{3}$ support are observed. The presence of $\mathrm{TiO}_{2}$ can improve the microstructure of $\mathrm{Al}_{2} \mathrm{O}_{3}$ support(B) surface and repair its defects, which contribute to synthesis of $\mathrm{NaA}$ zeolite membrane. Compared with $\mathrm{TiO}_{2} / \alpha-\mathrm{Al}_{2} \mathrm{O}_{3}$ support of uncoated seed, the surface defects of $\mathrm{TiO}_{2} / \alpha-\mathrm{Al}_{2} \mathrm{O}_{3}$ support $(\mathrm{C})$ of pre-coated seed have improved obviously. The pre-coated seeds with uniform and order basically cover the surface of the composite support. Pre-coated seed is a significant process for preparing $\mathrm{NaA}$ zeolite membrane. Since the particle size of $\mathrm{NaA}$ zeolite crystal is greater than the average pore size of $\mathrm{TiO}_{2} / \alpha-\mathrm{Al}_{2} \mathrm{O}_{3}$ support, it doesn `t lead 
crystal particles into support pores. So the pre-coated seed can effectively improve the surface properties of the support and provide a center for better synthesis of NaA zeolite membrane by hydrothermal crystallization.

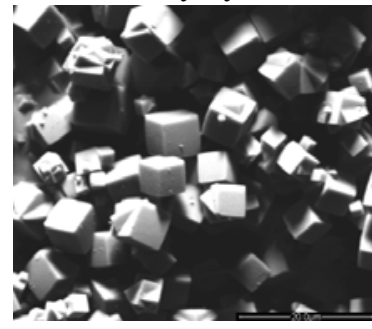

$\mathrm{A}(5000 \mathrm{X})$

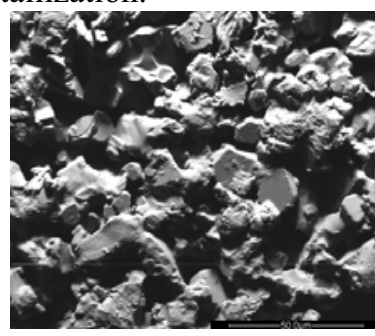

B (3000X)

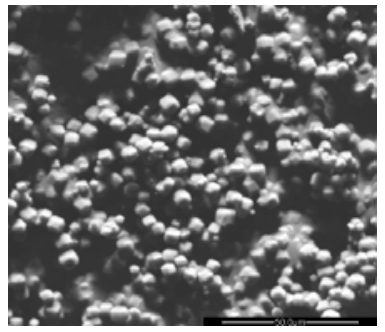

$\mathrm{C}(3000 \mathrm{X})$

Fig. 2 SEM images of the composite supports

\subsection{Structure of NaA zeolite membrane.}

Fig. 3 shows the XRD patterns of $\mathrm{NaA}$ zeolite membrane on the $\mathrm{TiO}_{2} / \alpha-\mathrm{Al}_{2} \mathrm{O}_{3}$ support. The characteristic peak of $\mathrm{NaA}$ zeolite membrane is consistent with standard characteristic peak of $\mathrm{NaA}$ zeolite, and there is no feature peak of $\mathrm{TiO}_{2} / \alpha-\mathrm{Al}_{2} \mathrm{O}_{3}$ support. This indicates that the support surface is completely covered by $\mathrm{NaA}$ zeolite membrane with no obvious defects on the surface of molecular sieve membrane prepared. In addition, there are no other impurity peaks in the $\mathrm{TiO}_{2} / \alpha-\mathrm{Al}_{2} \mathrm{O}_{3}$ support pattern. It also demonstrates that the $\mathrm{TiO}_{2}$ on the support surface has no effect on the crystallization of $\mathrm{NaA}$ synthesis liquid, and the $\mathrm{TiO}_{2}$ don`t change the synthesis process of NaA zeolite membrane.

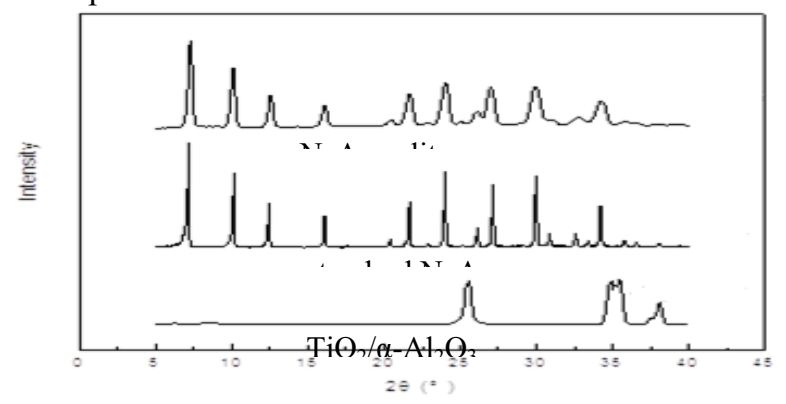

Fig. 3 XRD patterns of the NaA zeolite membranes

SEM images of the NaA zeolite membrane are showed in Fig. 4. The surface of $\mathrm{TiO}_{2} / \alpha-$ $\mathrm{Al}_{2} \mathrm{O}_{3}$ support is covered completely by $\mathrm{NaA}$ zeolite molecular sieve with crisscross grow together and cubic particles. There are no obvious defects between the crystal particles with complete crystal face. The size of crystal particle is approximate $6 \mu \mathrm{m}$ identical with $\mathrm{NaA}$ zeolite seed. The SEM cross-section image of NaA zeolite membrane shows that the membrane with a thickness of approximate $15 \mu \mathrm{m}$ is succession and no cracks. The membrane combines closely with support to connection together. The results indicate that the $\mathrm{NaA}$ zeolite molecular sieve membrane on $\mathrm{TiO}_{2} / \alpha-\mathrm{Al}_{2} \mathrm{O}_{3}$ composite support is prepared successfully by crystal seed method. 


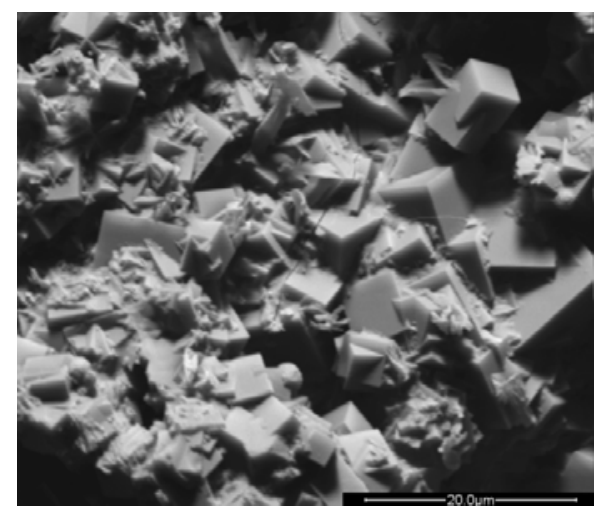

(a) Surface (5000X)

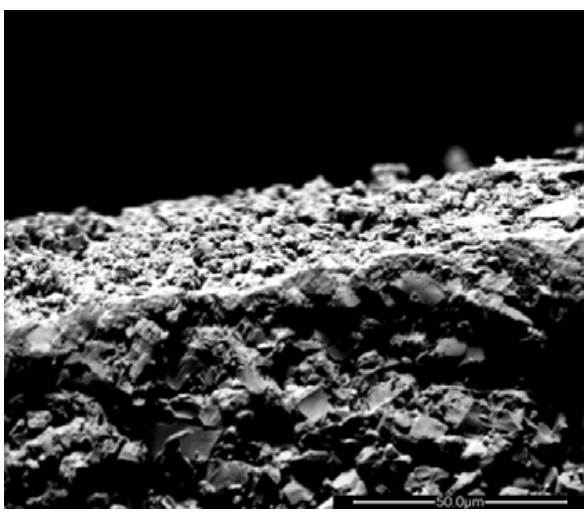

(b) Cross section (2000X)

Fig. 4 SEM images of the NaA zeolite membrane

\subsection{Oxygen permeability of $\mathrm{NaA}$ zeolite membrane.}

The oxygen permeability of $\mathrm{NaA}$ zeolite membrane is an important technical indicator for use to separation oxygen and nitrogen from air to preparation oxygen-enriched gas. Fig. 5 shows the curve of oxygen permeability of $\mathrm{NaA}$ zeolite membrane changing with pressure. The oxygen permeability of the membrane has no obvious change with the increase of pressure, which indicates that the mass transfer process of oxygen in molecular sieve membrane can't lead to viscous flow because of continuity and perfectness of the membrane. In the same conditions, the oxygen permeability of the NaA membrane on $\mathrm{TiO}_{2} / \alpha-\mathrm{Al}_{2} \mathrm{O}_{3}$ composite support is about $11 \times 10^{-5} \mathrm{~mol} /\left(\mathrm{m}^{2} \cdot \mathrm{s} \cdot \mathrm{Pa}\right)$ and increases of $47 \%$ compared with the oxygen permeability of $\alpha-\mathrm{Al}_{2} \mathrm{O}_{3}$ support, which further illustrates that oxygen permeability of the $\mathrm{NaA}$ zeolite membrane increases by $\mathrm{TiO}_{2}$ modifying the surface of $\alpha-\mathrm{Al}_{2} \mathrm{O}_{3}$ support. However, the oxygen and nitrogen separation performance of $\mathrm{NaA}$ zeolite molecular sieve membrane has still a large gap [15] compared with that of molecular sieve use for pressure swing adsorption process. To increase the separation performance and selectivity factor of $\mathrm{O}_{2} / \mathrm{N}_{2}$ of zeolite membrane, the research of new molecular sieve membrane materials and separation mechanism of oxygen and nitrogen should be strengthened.

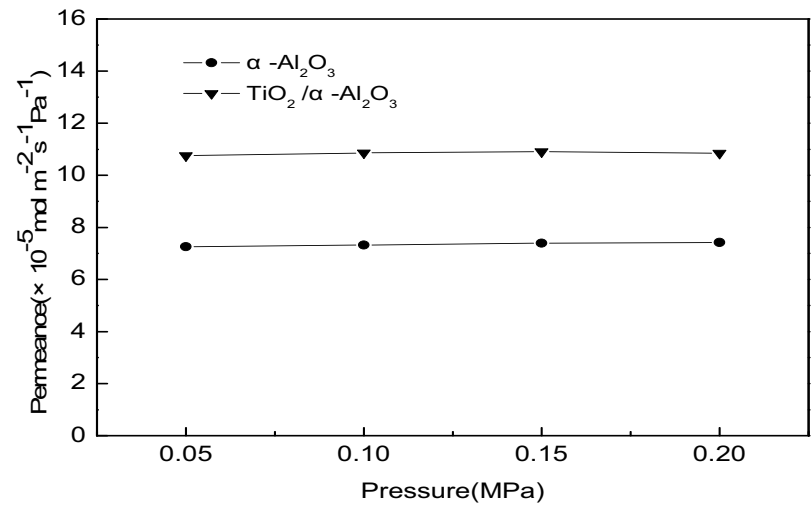

Figure 5 Oxygen permeability of the NaA zeolite membrane 


\section{Conclusions}

Using $\alpha-\mathrm{Al}_{2} \mathrm{O}_{3}$ porous tubular ceramic membrane as a support and $\mathrm{TiO}_{2}$ as modifier, the $\mathrm{TiO}_{2} / \alpha-\mathrm{Al}_{2} \mathrm{O}_{3}$ composite support was prepared by coating $\mathrm{TiO}_{2}$ sol on the surface of $\alpha$ $\mathrm{Al}_{2} \mathrm{O}_{3}$ support. The perfect and complete $\mathrm{NaA}$ zeolite membrane was synthesized on the surface of $\mathrm{TiO}_{2} / \alpha-\mathrm{Al}_{2} \mathrm{O}_{3}$ composite support with pre-coating seed layer by crystallization method. The $\mathrm{TiO}_{2}$ of the support surface not only has no effect on the crystallization of $\mathrm{NaA}$ synthesis liquid, and doesn 't change the synthesis process of NaA zeolite membrane, but also effectively improves the surface properties of the support, which no obvious defects between the crystal particles with size of approximate $6 \mu \mathrm{m}$. The perfect and complete $\mathrm{NaA}$ zeolite membrane combined closely with support to connection together with thickness of approximate $15 \mu \mathrm{m}$ was obtained. The oxygen permeability of the membrane on $\mathrm{TiO}_{2} / \alpha-\mathrm{Al}_{2} \mathrm{O}_{3}$ composite support improves of $47 \%$ compared with that of $\alpha$ $\mathrm{Al}_{2} \mathrm{O}_{3}$ support. So the process of $\mathrm{TiO}_{2}$ modifying the surface of $\alpha-\mathrm{Al}_{2} \mathrm{O}_{3}$ support should increase the oxygen permeability of the NaA zeolite membrane.

\section{Acknowledgments}

This research was financially supported by the Twelfth Five-year-plan Basic Research Project (No.CWS12J109).

\section{References}

1. Jin Wanqin, Xu Nanping. Design and application of oxygen-permeable membrane materials of mixed conducting oxides[J]. Chemical industry and engineering progress, 2006,25 (10):1143-1150.

2. Liu S L, Wang T H, Liu Q L, et al. Gas permeation properties of carbon molecular sieve membranes derived from novel poly(phthalazinone ether sulfone ketone) [J]. Ind. Eng. Chem. Res., 2008,47(3):876-880.

3. Zhang Bing, Yu Zhixue, Wang Tonghua, et al. Preparation and gas separation performance of hybrid carbon membranes from BPDA-ODA type polyimide and zeolites[J]. Membrane science and technology, 2013,33(3):33-37.

4. Fan Yiqun, Qi Hong, Xu Nanping. Advance in preparation techniques of porous ceramic membrane[J]. Journal of chemical industry and engineering, 2013,64(1):107112.

5. Sonia Aguado, Jorge Gascón, Jacobus C. Jansen, et al. Continuous synthesis of NaA zeolite membranes [J]. Microporous and Mesoporous Materials, 2009,120(12):170 176.

6. Changfeng Zeng, Lixiong Zhang, Xinhua Cheng, et al. Preparation and gas permeation of nano-sized zeolite NaA-filled carbon membranes [J]. Separation and Purication Technology, 2008, 63(3):628 633.

7. Marc Pera-Titus, Reyes Mallada, Joan Llorens, et al. Preparation of inner-side tubular zeolite NaA membranes in a semi-continuous synthesis system [J]. Journal of Membrane Science, 2006, 278(1-2):401 409.

8. Marc Pera-Titus, Joan Llorens, Fidel Cunill, et al. Preparation of zeolite NaA membranes on the inner side of tubular supports by means of a controlled seeding technique [J]. Catalysis Today, 2005, 104(2-4):281 287.

9. Afshin Pak, Toraj Mohammadi. Zeolite NaA membranes synthesis [J]. Desalination, 2006, 200(1-3):68 70.

10. Fan Yiqun, Xing Weihong. Progress in research on surface properties of ceramic 
membrane[J]. Membrane science and technology, 2013,33(5):1-7.

11. Aoki K, Kusakabe K, Morooka S. Gas permeation properties of A-type zeolite membrane formed on porous substrate by hydrothermal synthesis [J]. J.Membr.Sci., 1998, 141:197-205.

12. Lin Haiqiang, Chao Zisheng, Chen Guozhou, et al. Synthesis and gas separation performance of $\mathrm{NaA}$ zeolite composite membrane[J]. Chinese journal of catalysis, 2000, 5:471-474.

13. Linlin Yuwen, Mengfu Zhu, Hongbo Su,et al. Effects of synthesis parameters on hydrothermal synthesis of NaA zeolite[J].Advanced Materials Research, 2011,148148:1444-1448

14. Yuwen Linlin, Zhu Mmengfu, Su Hongbo, et al. Preparation and characterization of $\mathrm{NaA}$ zeolite membrane on macroporous $\alpha-\mathrm{A} 12 \mathrm{O} 3$ tube[J]. Journal of Tianjin Polytechnic University,2011,30(2):65-68.

15. ZHU Meng-fu, WANG Xing-peng, DENG Cheng, et al. Progress of Oxygen for Medicinal Use Production by Pressure Swing Adsorption Process[J]. Chinese Medical Equipment Journal, 2013,34(10):72-74. 